\title{
In vitro antibacterial and hemolytic activities of crotamine, a small basic myotoxin from rattlesnake Crotalus durissus
}

\begin{abstract}
Nancy Oguiura ${ }^{1}$, Malvina Boni-Mitake ${ }^{2}$, Regina Affonso ${ }^{3}$ and Guolong Zhang ${ }^{1}$
Crotamine, a myotoxin from the venom of South American rattlesnake, is structurally related to $\beta$-defensins, antimicrobial peptides (AMPs) found in vertebrate animals. Here, we tested the antibacterial properties of crotamine and found that it killed several strains of Escherichia coli, with the MICs ranging from 25 to $100 \mu \mathrm{g} \mathrm{m}^{-1}$. Time-kill and bacterial membrane permeabilization assays revealed that killing of bacteria by crotamine occurred within $1 \mathrm{~h}$ and reached the maximum by $2 \mathrm{~h}$. Additionally, the anti-E. coli activity of crotamine was completely abolished with $12.5 \mathrm{~mm} \mathrm{NaCl}$. Furthermore, the three intramolecular disulfide bonds of crotamine appeared dispensable for its antibacterial activity. The reduced form of crotamine was active against $E$. coli as well. However, crotamine showed no or weak activity up to $200 \mu \mathrm{g} \mathrm{ml}^{-1}$ against other species of Gram-negative and Gram-positive bacteria. Crotamine showed no appreciable hemolytic activity to erythrocytes. Our studies revealed that crotamine is also an AMP that kills bacteria through membrane permeabilization. However, crotamine appears to have a narrow antibacterial spectrum, distinct from many classical $\beta$-defensins, reinforcing the notion that crotamine originated from the $\beta$-defensin gene lineage, but has undergone significant functional diversification.
\end{abstract}

The Journal of Antibiotics (2011) 64, 327-331; doi:10.1038/ja.2011.10; published online 9 March 2011

Keywords: antimicrobial peptides; crotamine; $\beta$-defensin; snake venom; toxin

\section{INTRODUCTION}

Antimicrobial peptides (AMPs) constitute an important, phylogenetically conserved component of innate immunity in plants and animals. ${ }^{1,2}$ All AMPs share common features, such as small size (12-100 amino-acid residues), net positive charge and amphipathic structure. On the basis of structural similarities, AMPs can be broadly classified into two groups, that is, linear and cyclic peptides. Linear AMPs consist mainly of the peptides with an amphipathic $\alpha$-helical structure or a flexible structure with a high proportion of certain amino-acid residues, whereas cyclic AMPs include primarily the peptides containing one or more disulfide bridges with a loop or $\beta$-sheet structure. ${ }^{1,2}$ Besides constituting the majority of cyclic peptides, defensins comprise cysteine-rich $\alpha$ - and $\beta$-defensins in vertebrates, two major groups that differ in the spacing and disulfide bonding pattern of six cysteines. ${ }^{3,4}$

Besides a plethora of immunomodulatory activities, all defensins possess direct antimicrobial activities against a broad range of Gramnegative and Gram-positive bacteria, including antibiotic-resistant strains. ${ }^{3,4}$ Extensive studies on the mechanism of the antibacterial action of defensins have revealed that electrostatic interactions occur initially between the cationic peptides and the negatively charged bacterial membrane components, followed by peptide insertion, channel formation and disruption of membranes. ${ }^{5}$ Because of the presence of cholesterol and mostly zwitterinic phospholipids on eukaryotic membranes, AMPs are generally much less lytic to eukaryotic cells, with the antibacterial concentrations being mostly 10- to 100 -fold lower than cytotoxical concentrations.

Accumulating evidence indicated that defensins are phylogenetically conserved across a large spectrum of animal species. Polypeptides similar to $\beta$-defensins have been reported in the venoms of sea anemones, snakes and platypus, in which they display numerous pharmacological effects, including ion-channel inhibition and myonecrosis. ${ }^{6}$ Crotamine, a major myotoxin from the rattlesnake venom, is a 42 -amino-acid peptide ( $4.9 \mathrm{kDa}$, pI 9.5). ${ }^{7}$ Similar to $\beta$-defensins in mammals and birds, crotamine consists of six conserved cysteine residues forming the same pattern of disulfide bonds (cys1-cys5, cys2cys 4 and cys3-cys6) with a net positive charge of +8 , despite a low sequence homology (Figure 1). More importantly, crotamine is also structurally related to mammalian $\beta$-defensins by forming $2-3$ stranded antiparallel $\beta$-sheets with or without an $\alpha$-helix at the amino-terminus. ${ }^{6,8}$

Because of structural similarity with $\beta$-defensins, it is conceivable that crotamine might function as an AMP, in addition to being a myotoxin. Consistent with this prediction, three crotalic venoms were

${ }^{1}$ Department of Animal Science, Oklahoma State University, Stillwater, OK, USA; ${ }^{2}$ Gerência de Radioproteção, Instituto de Pesquisas Energéticas e Nucleares, IPEN, São Paulo, Brazil and ${ }^{3}$ Centro de Biotecnologia, Instituto de Pesquisas Energéticas e Nucleares, IPEN, São Paulo, Brazil 


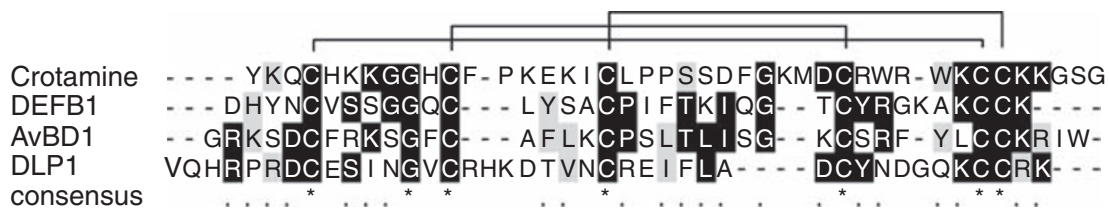

Figure 1 Amino-acid sequence alignment of crotamine with representative vertebrate $\beta$-defensins and $\beta$-defensin-like peptides. Dashes are introduced to maximize the alignment. Identical residues are shown in a black background, whereas conserved residues are shaded. The linkages of three intramolecular disulfide bonds are shown on top. AvBD1, avian $\beta$-defensin 1; DEFB1, human $\beta$-defensin 1; DLP1, platypus defensin-like peptide 2.

recently found to possess the anti-leishmanial activity, and crotamine was among the most active fractions with $50 \%$ killing of the promastigote forms of Leishmania amazonensis at approximately $20 \mu \mathrm{g} \mathrm{ml}^{-1}$.

In this study, we systematically evaluated the antibacterial properties of crotamine against a broad range of Gram-negative and Grampositive bacteria. The kinetics of bacterial killing and membrane permeabilization induced by crotamine was also examined. Recent studies have revealed that the three intramolecular disulfide bonds of $\beta$-defensins are dispensable for antibacterial activity, but required for chemotactic activity and for their resistance to protease degradation. ${ }^{10,11}$ In light of these surprising findings, the significance of the three intramolecular disulfide bonds in the antibacterial activity and hemolysis of crotamine was tested. We clearly revealed that besides structural similarity, the crotamine resembles $\beta$-defensins in its mode of action, but with a narrow antibacterial spectrum. Therefore, it is highly likely that crotamine and $\beta$-defensins share a common ancestry.

\section{MATERIALS AND METHODS}

\section{Purification and reduction of crotamine}

The crotalic venom from the snake Crotalus durissus terrrificus was purchased from CEVAP, Botucatu, São Paulo, Brazil, and used to purify crotamine as described, ${ }^{12}$ with slight modifications. Briefly, crotamine was purified from crude venom by size exclusion on a Sephacryl S200 column (GE Healthcare, Uppsala, Sweden), followed by cation exchange chromatography on a 1-ml Resource S on FPLC system (Akta Purifier System, GE Healthcare). The identity and purity of crotamine were confirmed by MS analysis.

To further test the impact of the three intramolecular disulfide bonds on its functional properties, purified crotamine was reduced by incubation with $5 \mathrm{~mm}$ dithiothreitol for $10 \mathrm{~min}$ at $100^{\circ} \mathrm{C}$ before the functional assays, as described below.

\section{Antibacterial assays}

A broad range of Gram-negative and Gram-positive bacteria were used to study the antibacterial spectrum of crotamine using a modified microbroth dilution assay. ${ }^{13}$ Gram-positive bacteria including Escherichia coli ATCC 25922, E. coli O157:H7 ATCC 700728, E. coli ML-35p (a gift from Richard Gallo, UCSD, La Jolla, CA, USA), Salmonella typhimurium ATCC 14028 and Pseudomonas aeruginosa ATCC 27853, and Gram-positive bacteria including Listeria monocytogenes ATCC 19115 and Staphylococcus aureus ATCC 25923 were tested. Briefly, overnight cultures of bacteria were subcultured in trypticase soy broth to the mid-logarithmic phase, washed once with $10 \mathrm{~mm}$ sodium phosphate buffer, $\mathrm{pH} 7.4$, and suspended to $4 \times 10^{5} \mathrm{CFU} \mathrm{ml}{ }^{-1}$ in the phosphate buffer containing $5 \%$ trypticase soy broth. Bacteria $(90 \mu \mathrm{l})$ were then mixed with $10 \mu \mathrm{l}$ of serial twofold dilutions of crotamine in duplicate in 96-well plates. After overnight incubation at $37^{\circ} \mathrm{C}$, the turbidity of the bacterial culture was read at $590 \mathrm{~nm}$. The MIC of each peptide was determined as the lowest concentration of crotamine that gave no visible bacterial growth.

The kinetics of bacterial killing was tested against E. coli ATCC 25922 and S. aureus ATCC $25923 .{ }^{13}$ Briefly, $25 \mu \mathrm{g} \mathrm{ml}^{-1}$ of native or reduced crotamine was incubated with E. coli ATCC 25922 for 0, 15, 30, 60 and $120 \mathrm{~min}$ at $37^{\circ} \mathrm{C}$ in $10 \mathrm{~mm}$ sodium phosphate buffer, $\mathrm{pH}$ 7.4. The reaction was stopped by addition of 9 volumes of ice-cold phosphate-buffered saline (PBS), followed by serial 10-fold dilutions and plating on trypticase soy agar plates. Viable bacterial colonies were counted after overnight growth at $37^{\circ} \mathrm{C}$. For time-kill assay of S. aureus, $100 \mu \mathrm{g} \mathrm{ml}^{-1}$ of native crotamine was used and plated after 60 and $120 \mathrm{~min}$ of incubation, followed by serial plating and counting of viable bacterial colonies.

To study the effect of salinity on the antibacterial activity of crotamine, a modified microbroth dilution assay was used ${ }^{13}$ by incubating the native $\left(50 \mu \mathrm{g} \mathrm{ml}^{-1}\right)$ or reduced form $\left(25 \mu \mathrm{g} \mathrm{ml}^{-1}\right)$ of crotamine with E. coli ATCC 25922 in $10 \mathrm{~mm}$ sodium phosphate buffer containing 5\% trypticase soy broth and different concentrations of $\mathrm{NaCl}(0,12.5,25,50,100$ and $150 \mathrm{~mm})$. The lowest $\mathrm{NaCl}$ concentration that gave no visible bacterial growth was recorded.

\section{Bacterial membrane permeabilization assay}

The kinetic disruption of bacterial cytosolic membranes was measured in E. coli ML-35p, a strain that contains a plasmid giving constitutive expression of $\beta$-galactosidase in the cytosol, but lacks lactose permease. ${ }^{14,15}$ Briefly, bacteria at the mid-logarithmic phase were washed twice in $10 \mathrm{~mm}$ sodium phosphate buffer, $\mathrm{pH} 7.4$, diluted to $0.03 A_{600 \mathrm{~nm}}$ (equivalent to $2.5-5 \times 10^{7} \mathrm{CFU} \mathrm{ml}^{-1}$ ) in the same buffer containing $1 \%$ trypticase soy broth. In a $96-$ well tissue culture plate, $80 \mu \mathrm{l}$ bacteria was then mixed with native or reduced crotamine to a final concentration of $50 \mu \mathrm{g} \mathrm{ml}^{-1}$, followed by addition of $1.5 \mathrm{~mm}$ of a chromogenic substrate, $o$-nitrophenyl- $\beta$-D-galactopyranoside (Sigma, St Louis, MO, USA), to a total volume of $100 \mu \mathrm{l}$ per well. The plate was incubated at $37^{\circ} \mathrm{C}$ in a Multiskan Spectrum microplate spectrophotometer (Thermo Scientific, Waltham, MA, USA) with periodic shaking. The production of $o$-nitrophenol was monitored at $420 \mathrm{~nm}$ every $2 \mathrm{~min}$ for up to $2 \mathrm{~h}$.

\section{Hemolysis assay}

The hemolytic activity of crotamine was determined in fresh mouse blood in the presence or absence of $10 \%$ fetal bovine serum. ${ }^{13}$ Briefly, EDTAanticoagulated blood was collected from 6- to 10-week-old, BALB/c mice, washed twice with PBS, and diluted to $0.5 \%$ in PBS with and without $10 \%$ fetal bovine serum, followed by dispensing $90 \mu \mathrm{l}$ into 96 -well plates. Serially diluted crotamine $(10 \mu \mathrm{l})$ was added in duplicate to erythrocytes and incubated at $37^{\circ} \mathrm{C}$ for $2 \mathrm{~h}$. Following centrifugation at $800 \mathrm{~g}$ for $10 \mathrm{~min}$, the supernatants were transferred to new 96-well plates, and absorbance measured at $405 \mathrm{~nm}$ for released hemoglobin. Controls for 0 and $100 \%$ hemolysis consisted of cells suspended in PBS only and in $1 \%$ Triton X-100, respectively. The percentage of hemolysis was calculated as $\left[\left(A_{405} \mathrm{~nm}\right.\right.$, crotamine $\left.-A_{405} \mathrm{~nm}, \mathrm{PBS}\right) /$ $\left(A_{405 \mathrm{~nm}, 1 \%}\right.$ Triton X-100- $\left.\left.A_{405 \mathrm{~nm}, \mathrm{PBS}}\right)\right] \times 100$.

\section{RESULTS}

\section{Antibacterial properties of crotamine}

Five Gram-negative and two Gram-positive bacteria were used to test the antibacterial spectrum of crotamine, as previously described. ${ }^{13}$ Crotamine showed a MIC of 25,50 and $100 \mu \mathrm{g} \mathrm{ml}^{-1}$ against three E. coli strains (O157:H7, ML-35p and ATCC 25922), respectively, whereas no complete inhibition bacterial growth was observed against two other Gram-negative bacteria (Pseudomonas aeruginosa and Salmonella typhimurium) and two Gram-positive bacteria (S. aureus and L. monocytogenes) at concentrations up to $200 \mu \mathrm{g} \mathrm{ml}^{-1}$, following overnight incubation at $37^{\circ} \mathrm{C}$ (Table 1 ). The results clearly suggested that crotamine is an AMP. However, unlike mammalian $\beta$-defensins active against a broad range of bacteria, crotamine is a narrow- 
Table 1 MIC of native and reduced crotamine ${ }^{a}$

\begin{tabular}{lcrc}
\hline & & \multicolumn{2}{c}{ MIC $\left.(\mu \mathrm{gm})^{-1}\right)$} \\
\cline { 3 - 4 } Bacteria & ATCC no. & Crotamine & Reduced crotamine \\
\hline Gram-negative & & & \\
Escherichia coli 0157:H7 & 700728 & 25 & 25 \\
E. coli ML-35p & & 50 & 25 \\
E. coli & 25922 & 100 & 50 \\
Pseudomonas aeruginosa & 27853 & $>200$ & NT \\
Salmonella typhimurium & 14028 & $>200$ & NT \\
& & & $>200$ \\
Gram-positive & & $>200$ & NT \\
Staphylococcus aureus & 25923 & $>200$ & \\
Listeria monocytogenes & 19115 & &
\end{tabular}

Abbreviation: NT, not tested.

aThe MIC values were determined by a modified microbroth dilution assay ${ }^{13}$ using native or reduced crotamine.

spectrum peptide antibiotic with preferences toward certain bacterial species.

To further study the kinetics of bacterial killing, $25 \mu \mathrm{g} \mathrm{ml}^{-1}$ of crotamine (or $1 \times$ MIC concentration) was incubated with $E$. coli ATCC 25922 for various times, and surviving bacteria were counted by serial plating, as described. ${ }^{13}$ Crotamine showed a modest $20 \%$ killing at $30 \mathrm{~min}$ following exposure to E. coli (Figure 2a). Approximately a $1-\log$ reduction was observed $60 \mathrm{~min}$ upon exposure, with a dramatic 3-log reduction of $E$. coli occurring at $2 \mathrm{~h}$ (Figure 2a). Although crotamine is unable to completely suppress the growth of $S$. aureus ATCC 25923 after overnight incubation even at $200 \mu \mathrm{g} \mathrm{ml}^{-1}$ (Table 1), there was an obvious 1-log reduction in the bacterial counts following $2 \mathrm{~h}$ of exposure to $100 \mu \mathrm{g} \mathrm{ml}^{-1}$ of crotamine (Figure $2 \mathrm{~b}$ ). However, it is noted that killing of $S$. aureus by crotamine is slower than that of E. coli and did not proceed until $60 \mathrm{~min}$. Furthermore, reminiscent of defensins, ${ }^{3,4}$ the antibacterial activity of crotamine was sensitive to salt, as inclusion of as low as $12.5 \mathrm{~mm}$ of $\mathrm{NaCl}$ failed to inhibit the growth of $E$. coli in a modified microbroth dilution assay (data not shown).

To examine the mechanism of action and confirm the bacterialkilling kinetics, $50 \mu \mathrm{g} \mathrm{ml}^{-1}$ (or $1 \times$ MIC concentration) of crotamine was incubated with E. coli ML-35p, which constitutively expresses cytosolic $\beta$-galactosidase, in the presence of a chromogenic substrate. The medium color change, proportional to the degree of permeabilization of bacterial cytosolic membranes due to the release of $\beta$-galactosidase, was monitored at $A_{420 \mathrm{~nm}}$ every $2 \mathrm{~min}$ for up to $2 \mathrm{~h}$. As compared with the control, no obvious membrane lysis occurred until 50-60 min following addition of crotamine to bacteria, and the membrane lysis became highly prevalent at $2 \mathrm{~h}$ (Figure 3 ), consistent with the earlier time-kill assay (Figure 2a). The results indicated that, like defensins, crotamine kills bacteria primarily through membrane permeabilization.

\section{Impact of the disulfide bonds on the antibacterial properties} of crotamine

To test the impact of the intramolecular disulfide bonds on the antibacterial activity, native crotamine was reduced with dithiothreitol. As shown in Table 1, reduced crotamine showed slightly enhanced antibacterial activity toward three $E$. coli strains, relative to the native crotamine. The time-kill assay further revealed that $25 \mu \mathrm{g} \mathrm{ml}^{-1}$ reduced crotamine gave a 1-log reduction in E. coli O157:H7 counts at as early as $15 \mathrm{~min}$, and a nearly complete elimination of bacteria occurred at $60 \mathrm{~min}$ following incubation, with the bacterial counts
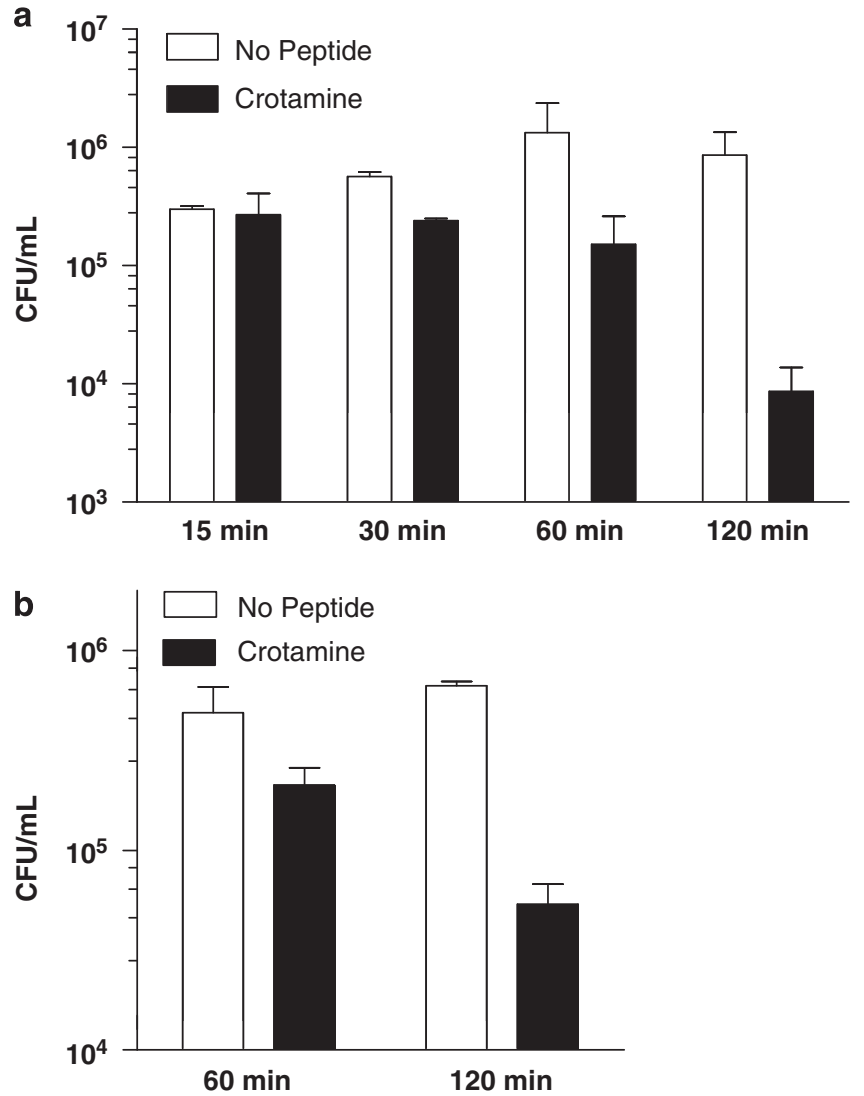

Figure 2 Kinetics of bacterial killing by crotamine. E. coli 0157:H7 (a) or S. aureus ATCC 25923 (b) at $5 \times 10^{5} \mathrm{CFU} \mathrm{ml}^{-1}$ was incubated with or without $25 \mu \mathrm{g} \mathrm{ml}^{-1}$ (a) or $100 \mu \mathrm{g} \mathrm{m} l^{-1}$ (b) of crotamine for different times at $37^{\circ} \mathrm{C}$, followed by bacterial enumeration. The results represent means \pm s.e.m. of three independent experiments.

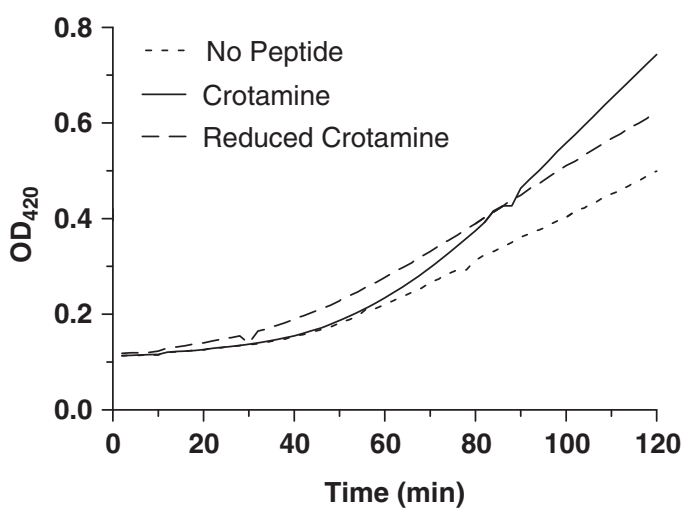

Figure 3 Inner membrane permeabilization capacity of crotamine. E. coli ML35p, which constitutively expresses $\beta$-galactosidase in the cytosol, was incubated with $50 \mu \mathrm{g} \mathrm{ml}^{-1}$ of native or reduced crotamine. Permeabilization of bacterial inner membranes as indicated by the release of cytosolic $\beta$-galactosidase to the cell culture medium was measured at $\mathrm{OD}_{420 \mathrm{~nm}}$ in the presence of a chromogenic substrate, 0 -nitrophenyl- $\beta$-D-galactopyranoside every $2 \mathrm{~min}$ for up to $2 \mathrm{~h}$. The results represent means \pm s.e.m. of two independent experiments.

being below the limit of detection, which is $200 \mathrm{CFU} \mathrm{ml}^{-1}$ (Figure 4). This bacterial-killing kinetics of reduced crotamine was further confirmed by the inner membrane permeabilization assay. Enhanced release of $\beta$-galactosidase and therefore cytoplasmic membranes 


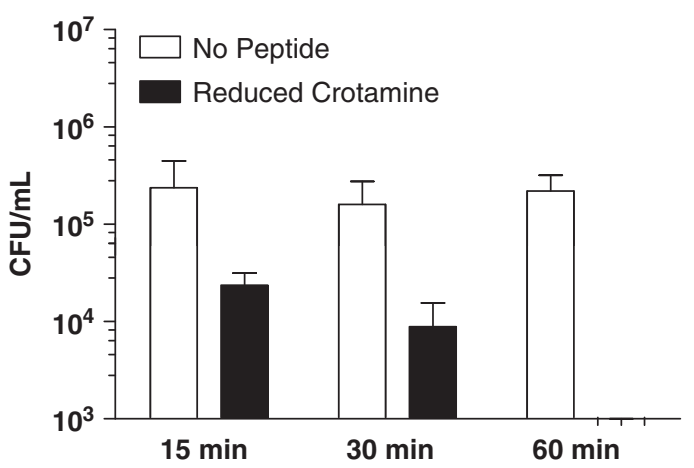

Figure 4 Kinetics of bacterial killing by reduced crotamine. E. coli 0157:H7 at $5 \times 10^{5} \mathrm{CFU} \mathrm{ml}^{-1}$ was incubated with or without $25 \mu \mathrm{g} \mathrm{ml}^{-1}$ of reduced crotamine for different times at $37^{\circ} \mathrm{C}$, followed by bacterial enumeration. The results represent means \pm s.e.m. of three independent experiments.

occurred 10 min following bacterial exposure to reduced crotamine (Figure 3). Furthermore, reduced crotamine showed slightly enhanced resistance to salt, as the anti-E. coli activity was not completely inhibited until the final $\mathrm{NaCl}$ concentration reached $50 \mathrm{~mm}$, as opposed to $12.5 \mathrm{~mm}$ with native crotamine (data not shown).

Collectively, our results clearly indicated that the presence of intramolecular disulfide bonds is dispensable for the antibacterial activity of crotamine and even adversely affects its efficacy in membrane disruption. This may occur because of possible oligomerization of native crotamine, ${ }^{16}$ thereby reducing its effective concentration and efficacy in membrane disruption. However, SDS-PAGE under nonreducing conditions showed only one band in native crotamine, indicating no obvious aggregation in our hands (data not shown). Therefore, the enhanced activity of reduced crotamine might be explained by its altered structure, which may facilitate the interactions of the peptide with bacterial membranes.

\section{Hemolytic activity of native and reduced crotamine}

To further test their capacity to permeabilize mammalian cell membranes, both native and reduced forms of crotamine were tested for their hemolytic activity toward mouse erythrocytes with and without fetal bovine serum. No appreciable hemolysis was observed with native crotamine up to $1024 \mu \mathrm{g} \mathrm{ml}^{-1}$, the highest concentration tested (Figure 5), which is consistent with the cytotoxicities of defensins, regardless of serum. Only reduced crotamine presented a dose-dependent hemolytic activity in the presence of $10 \%$ fetal bovine serum, showing $35 \%$ hemolysis at $1024 \mu \mathrm{g} \mathrm{ml}^{-1}$ (Figure 5). It was consistent with earlier antibacterial assays that found that an increased membrane-lytic efficacy was associated with the reduced form of crotamine. Surprisingly, reduced crotamine exhibited virtually no hemolysis to erythrocytes in the absence of serum, implying that certain serum proteins might facilitate the interactions of reduced crotamine with membranes. This indirect hemolytic activity was observed in many snake venoms ${ }^{17}$ that also were not able to hemolysate in the absence of serum. Cadillo et al. ${ }^{18}$ and Jeng et al. ${ }^{19}$ suggested crotoxin, a phospholipase $\mathrm{A}_{2}$ from rattlesnake venom, as the toxin responsible for this indirect activity. Crotamine shares with crotoxin a cationic region $(+00+++00+)$ responsible for myotoxicity. ${ }^{20}$

\section{DISCUSSION}

Because of the conservation of the cysteine-spacing pattern and spatial structure, it is speculated that crotamine, a well-known rattlesnake

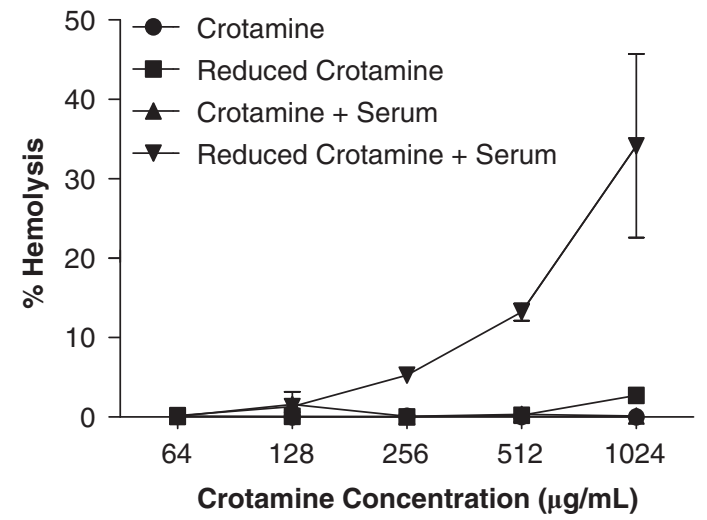

Figure 5 Hemolysis assay. Hemolytic activity of native or reduced crotamine with or without $10 \%$ serum (fetal bovine serum). The lysis of erythrocytes was monitored for the release of hemoglobin at $A_{405 \mathrm{~nm}}$, following incubation of blood with serially diluted crotamine.

venom myotoxin, may resemble vertebrate $\beta$-defensins by also acting as an AMP. ${ }^{21}$ Besides the modest anti-leishmanial activity seen with crotalic venoms, ${ }^{9}$ no definitive evidence on the antibacterial activity of crotamine has been shown before the initiation of the present study. Following our comprehensive testing on the antibacterial and cytotoxic properties, we now can unequivocally conclude that crotamine is also a $\beta$-defensin-like AMP with a salt-sensitive antibacterial activity. To strengthen our conclusion, an independent study also demonstrated the antibacterial activity of crotamine ${ }^{22}$ during the preparation of this manuscript.

Similar to $\beta$-defensins, crotamine kills bacteria through membrane permeabilization that is independent of the integrity of disulfide bonding. In contrast, reduced crotamine even demonstrated an enhanced capacity in disruption of bacterial membranes (Figure 3). It is possible that the three intramolecular disulfide bridges of crotamine may prove beneficial for other biological functions such as myotoxicity and in vivo stability. Indeed, the lethality of unfolded crotamine was shown to be reduced by approximately $50 \%{ }^{12}$

Interestingly, crotamine appears to be active against only a narrow spectrum of bacteria, in contrast with most vertebrate $\beta$-defensins that are broadly active. This is perhaps not surprising, given a great degree of diversity in the primary amino-acid sequence between crotamine and $\beta$-defensins (Figure 1). In our study, among five Gram-negative and two Gram-positive bacterial strains that we tested, crotamine showed an obvious bactericidal activity only against E. coli, with a weak or no activity against all others in the MIC assay, although the time-kill assay revealed a weak activity against $S$. aureus. Consistent with our results, Yount et al. ${ }^{22}$ reported the antibacterial activity of crotamine against $E$. coli, but not $S$. aureus, using a radial diffusion method. In the same study, the activity against a Gram-positive (Bacillus subtilis) and fungal (Candida albicans) pathogen was also observed with crotamine.

The physiological significance of the narrow antimicrobial activity of crotamine remains to be studied, given the presence of a wide range of bacterial species including Pseudomonas, Salmonella, Aerobacter, Bacillus, Citrobacter, Clostridium, Enterobacter and Streptococcus in the mouth, fangs and/or venom of Bothrops jararaca and North and South American rattlesnakes. ${ }^{23,24,25,26}$ It is tempting to speculate that crotamine and isoforms ${ }^{27}$ or paralogs such as crotasin ${ }^{28}$ may have a complementary antimicrobial spectrum.

We revealed in this study that crotamine possesses antimicrobial activities. Reciprocally, it is interesting to see whether $\beta$-defensins also 
behave like a myotoxin through activation of voltage-sensitive ion channels. Indeed, similar to crotamine, a $\beta$-defensin was shown to interact with $\mathrm{K}^{+}$channels, albeit with a different specificity. ${ }^{22}$ Although hBD-2, a human $\beta$-defensin, interacted with both prokaryotic and eukaryotic voltage-sensitive $\mathrm{K}^{+}$channels, crotamine only interacted with eukaryotic $\mathrm{K}^{+}$channels. ${ }^{22}$ The amino-acid sequence variation between crotamine and $\beta$-defensins may explain their difference in ion channel targeting.

Taken together, our results showing the antibacterial activity of crotamine reinforce the notion that crotamine evolved from the duplication of the $\beta$-defensin gene lineage. Coupled with its weak hemolytic activity, crotamine and other snake venom toxins may have potential for further development as therapeutics in the face of dwindling of effective antimicrobial drugs in the twenty-first century.

\section{ACKNOWLEDGEMENTS}

We are grateful to Poliana G Corrêa for her assistance with electrophoresis assays. This project was supported by a postdoctoral fellowship award (to NO) from FAPESP, S. Paulo, Brazil, and USDA CSREES grant (2008-35204-04544), Oklahoma Center for the Advancement of Science and Technology grants (HR07-113 and AR07.2-087) and Oklahoma Agricultural Experiment Station (H-2507).

1 Lai, Y. \& Gallo, R. L. AMPed up immunity: how antimicrobial peptides have multiple roles in immune defense. Trends Immunol. 30, 131-141 (2009).

2 Zasloff, M. 2002. Antimicrobial peptides of multicellular organisms. Nature 415, 389395 (2009).

3 Ganz, T. Defensins: antimicrobial peptides of innate immunity. Nat. Rev. Immunol. 3, 710-720 (2003).

4 Selsted, M. E., \& Ouellette, A. J. Mammalian defensins in the antimicrobial immune response. Nat. Immunol. 6, 551-557 (2005).

5 Andreu, D. \& Rivas, L. Animal antimicrobial peptides: an overview. Biopolymers 47, 415-433 (1998).

6 Torres, A. M. \& Kuchel, P. W. The $\beta$-defensin-fold family of polypeptides. Toxicon 44, 581-588 (2004).

7 Oguiura, N., Boni-Mitake, M. \& Rádis-Baptista, G. New view on crotamine, a small basic polypeptide myotoxin from South American rattlesnake venom. Toxicon 46, 363-370 (2005).

8 Fadel, V. et al. Automated NMR structure determination and disulfide bond identification of the myotoxin crotamine from Crotalus durissus terrificus. Toxicon 46, 759-767 (2005).
9 Passero, L. F. D., Tomokane, T. Y., Corbett, C. E. P., Laurenti, M. D. \& Toyama, M. H. Comparative studies of the anti-leishmanial activity of three Crotalus durissus ssp. venoms. Parasitol. Res. 101, 1365-1371 (2007).

10 Hoover, D. M., Wu, Z., Tucker, K., Lu, W. \& Lubkowski, J. Antimicrobial characterization of human $\beta$-defensin 3 derivatives. Antimicrob. Agents Chemother. 47, 2804-2809 (2003).

$11 \mathrm{Wu}, \mathrm{Z}$. et al. Engineering disulfide bridges to dissect antimicrobial and chemotactic activities of human $\beta$-defensin 3. Proc. Natl Acad. Sci. USA 100, 8880-8885 (2003).

12 Boni-Mitake, M., Costa, H., Spencer, P. J., Vassillieff, V. S. \& Rogero, J. R. Effects of ${ }^{60} \mathrm{Co}$ gamma radiation on crotamine. Braz. J. Med. Biol. Res. 34, 1531-1538 (2001).

$13 \mathrm{Xiao}, \mathrm{Y}$. et al. Identification and functional characterization of three chicken cathelicidins with potent antimicrobial activity. J. Biol. Chem. 281, 2858-2867 (2006).

14 Bommineni, Y. R. et al. Fowlicidin- 3 is an $\alpha$-helical cationic host defense peptide with potent antibacterial and lipopolysaccharide-neutralizing activities. FEBS J. 274, 418-428 (2007).

15 Xiao, Y. et al. The central kink region of fowlicidin-2, an alpha-helical host defense peptide, is critically involved in bacterial killing and endotoxin neutralization. J. Innate Immun. 1, 268-280 (2009).

16 Teno, A. M., Vieira, C. A., Santoro, M. M., Neves, A. G. \& Giglio, J. R. Interchain disulfide bonds in crotamine self-association. J. Biochem. 107, 821-825 (1990).

17 Rosenfeld, G., Kelen, E. M. A. \& Nudel, F. Hemolytic activity of animal venoms. I. Classification in different types and activities. Mem. Inst. Butantan 30, 103-116 (1960-1962).

18 Cadillo, E. M., Ferreyra, C. B. \& Zavaleta, A. Actividad hemolítica de venenos de serpientes de los géneros Bothrops, Lachesis, Crotalus y Micrurus. (Serpentes: Viperidae y Elapidae).. Rev. Biol. Trop. 39, 311-314 (1991).

19 Jeng, T.- W., Hendon, R. A., \& Fraenkel-Conrat, H Search for relationships among the hemolytic, phospholipolytic, and neurotoxic activities of snake venoms. Proc. Natl Acad. Sci. USA 75, 600-604 (1978).

20 Kini, R. M. \& Iwanaga, S. Structure- function relationships of phospholipases II: charge density distribution and the myotoxicity of presynaptically neurotoxic phospholipases. Toxicon 24, 895-905 (1986)

21 Yeaman, M. R. \& Yount, N. Y. Unifying themes in host defence effector polypeptides. Nat. Rev. Microbiol. 5, 727-740 (2007).

22 Yount, N. Y. et al. Selective reciprocity in antimicrobial activity versus cytotoxicity of hBD-2 and crotamine. Proc. Natl Acad. Sci. USA 106, 14972-14977 (2009).

23 Garcia-Lima, E. \& Laure, C. J. A study of bacterial contamination of rattlesnake venom. Rev. Soc. Bras. Med. Trop. 20, 19-21 (1987).

24 Goldstein, E. J. C., Citron, D. M., Gonzalez, H., Russell, F. E. \& Finegold, S. M. Bacteriology of rattlesnake venom and implications for therapy. J. Infect. Dis. 140, 818-821 (1979).

25 Jorge, M. T. et al. Flora bacteriana da cavidade oral, presas e veneno de Bothrops jararaca: possível fonte de infecção no local da picada. Rev. Inst. Med. Trop. São Paulo 32, 6-10 (1990).

26 Ledbetter, E. O. \& Kutscher, A. E. The aerobic and anaerobic flora of rattlesnake fangs and venom. Arch. Environ. Health 19, 770-778 (1969).

27 Oguiura, N., Collares, M. A., Furtado, M. F. D., Ferrarezzi, H. \& Suzuki, H. Intraspecific variation of the crotamine and crotasin genes in Crotalus durissus rattlesnakes. Gene 446, 35-40 (2009).

28 Rádis-Baptista, G. et al. Identification of crotasin, a crotamine-related gene of Crotalus durissus terrificus. Toxicon 43, 751-759 (2004). 